This is an Accepted Manuscript of an article published by Elsevier in Research in Social Stratification and Mobility on April 2017, available online: https://doi.org/10.1016/j.rssm.2016.12.002.

\title{
Intergenerational Transmission of Educational Attainment in
}

\section{Adoptive Families in the Netherlands}

Lotte Scheeren $^{\mathrm{a}, 1}$, Marjolijn Das ${ }^{\mathrm{b}}$, Aart C. Liefbroer ${ }^{\mathrm{c}}$

${ }^{a}$ Department of Sociology, University of Amsterdam, The Netherlands

${ }^{b}$ Statistics Netherlands (CBS), The Hague, The Netherlands, Department of Human

Geography, Planning and International Development, University of Amsterdam, The

Netherlands

${ }^{\mathrm{c}}$ Netherlands Interdisciplinary Demographic Institute, The Hague, The Netherlands, Department of Epidemiology, University Medical Centre Groningen, University of Groningen, The Netherlands, and Department of Sociology, Vrije Universiteit Amsterdam, The Netherlands

\footnotetext{
${ }^{1}$ Corresponding author at University of Amsterdam, Nieuwe Achtergracht 166, 1018 WV Amsterdam. P.O. Box 15508, 1001 NA Amsterdam, The Netherlands.

E-mail address: L.Scheeren@uva.nl
} 


\title{
Intergenerational Transmission of Educational Attainment in
}

\author{
Adoptive Families in the Netherlands
}

\begin{abstract}
To improve our understanding of the mechanisms underlying the strong association between family background and children's educational attainment, we examined intergenerational transmission within families where genetic transmission is absent. Specifically, we investigated the effect of parent's education and income on the educational attainment of their foreign-born adopted children. A large-scale register database was used, which contains information on the adoption status, educational level in secondary school and parental characteristics of all 15-year old children living in the Netherlands in the years 2011-2013. This study demonstrated that parental education mainly influenced their children's education when they were genetically related and that the influence was weak when they were adopted. Parental income, on the other hand, affected both adopted and biological children's educational attainment. Hence, the results suggested that genetic transmission and economic capital play a substantial role in intergenerational transmission of educational attainment.
\end{abstract}

Keywords: intergenerational transmission, educational attainment, foreign-born adopted children 


\section{Introduction}

For decades, scholars have examined the effect of family background on the educational achievement of children (Blau \& Duncan, 1967; Haveman \& Wolfe, 1995). In general, the evidence indicated strong correlations between the educational performance of children and the educational attainment and income of their parents. Different mechanisms have been suggested to underlie this strong intergenerational transmission. First, parents may influence their children's educational attainment via the transmission of cultural capital (e.g. the transfer of knowledge, skills, behaviours etc.) (Bourdieu, 1973). Second, parents' financial capital can be important (Becker \& Tomes, 1986). Higher-income parents have more resources to invest in their children, which can benefit children's academic performance. And a third possible cause is hereditary factors; since cognitive abilities and IQ are partially inherited, the similarity between parents and children can be the outcome of genetic transmission (Anger \& Heineck, 2010; Leibowitz, 1974). Disentangling these three mechanisms is, however, difficult due to the interrelatedness of the indicators.

To separate the underlying mechanisms and improve our understanding of the role of genetic factors in intergenerational transmission of education and income, three different research strategies have been applied in recent studies (Holmlund, Lindahl \& Plug, 2011). First, some studies examined twins. For instance, they compared monozygotic and dizygotic twins, as their difference in similarity can be attributed to genetic influence (De Zeeuw, De Geus \& Boomsma, 2015), or they studied identical twins who were reared apart, since their differences can be ascribed to environmental influences (Bouchard, Lykken, McGue, Segal, \& Tellegen, 1990). Second, some studies utilized adoptees. As genetic transmission is absent within adoptive families, genetic factors cannot cause the observed correlation between parental and child's education and occupation (Björklund, Lindahl \& Plug, 2006; Liu \& 
Zeng, 2009). And third, some studies investigated intergenerational effects with the use of instrumental variables, such as educational reforms (Black, Devereux \& Salvanes, 2005; Oreopoulos, Page \& Stevens, 2006).

This paper focuses on the adoption strategy. In general, previous research on intergenerational transmission within adoptive families observed a significant correlation between the educational and income levels of adoptive parents and the education and income of their adopted children (e.g., Björklund, Jäntti \& Solon, 2007; Plug \& Vijverberg, 2003). These studies demonstrated the importance of family environment on children's schooling and income, even in the absence of a genetic relation. However, these studies also indicated the importance of genetics, since the intergenerational effect was weaker for adoptive families than for families with biologically related children.

Prior studies on intergenerational transmission within adoptive families have also left a number of questions unanswered. First, nearly all prior research examined mainly national adoptees (e.g., Björklund et al., 2007; Plug, 2004). However, native-born adoptees are possibly not randomly assigned to their adoptive home. National adoptions might include children adopted by relatives, or adoption agencies used corresponding characteristics of the natural and adoptive parents as a matching strategy (Scarr \& Weinberg, 1994). Hence, studies examining native-born adoptees potentially overestimate the environmental effect. A strategy to control for selective placement is investigating international adoptees ${ }^{2}$. Foreign-born adoptees are much less likely to be genetically related to the adoptive parents, and selective placement is nearly impossible due to a general lack of information about the biological parents (Holmlund et al., 2011). The few studies that examined foreign-born adoptees provided inconsistent results. Whereas Sacerdote (2007) showed that parental education

\footnotetext{
${ }^{2}$ Another strategy to control for selective placement is including information about the adoptive parents as well as the biological parents (Björklund et al., 2006). However, even if any information is available about the biological parents, this is generally only the case for national adoptions. Since the number of national adoptions is nowadays very low, this strategy has become impossible to implement with recent data.
} 
strongly affected the educational attainment of foreign-born adoptees in the United States, much smaller and even insignificant effects were found in studies implemented in Scandinavian countries (Haegeland, Kirkeboen, Raaum \& Salvanes, 2010; Björklund \& Richardson, 2001). Hence, our first aim is to examine intergenerational transmission of education between parents and their foreign-born adopted children.

Second, almost all previous studies focused on adopted children born (long) before 1980 (e.g., Björklund \& Richardson, 2001; Björklund et al., 2006; Sacerdote, 2007). Their respondents were already adults at the time of the interview and went to school years ago. However, in the past decades school systems, average educational levels, openness of societies and gender equality have all changed (Erikson \& Rudolphi, 2010; Peter \& Horn, 2005), potentially leading to a change in the strength of intergenerational transmission as well. Therefore, the second aim is to investigate the effect of parental characteristics on their adopted children's educational attainment in a young cohort of children that have been enrolled in secondary education only recently.

Finally, prior research was conducted in a very limited number of countries, i.e. Sweden, Norway and the United States. Given that the strength of intergenerational transmission between biological parents and children is known to vary across countries (Blanden, 2013; Solon, 2002), it could be argued that context also matters for the study of transmission within adoptive families. Societies with high inequality generally have low intergenerational mobility: in these countries the family environment has a stronger influence on children's outcomes than in countries with low inequality (Blanden, 2013). Therefore, a third aim of this study is to test the strength of transmission among adoptive parents and children in a new context, i.e. the Netherlands. Inequality in the Netherlands is relatively low compared to the US, but relatively high compared to Sweden (OECD, 2011). Hence, ceteris 
paribus, it could be expected that intergenerational non-genetic transmission in the Netherlands is stronger than in Sweden, but weaker than in the US.

In summary, this study examines the effect of family background, in particular of parental education and income, on the educational attainment of foreign-born adoptees in the Netherlands. Focusing on internationally adopted children born between 1995 and 1998 enables us to investigate the parental effect on a recent cohort of school-aged children. Our central research question is: "To what extent is the educational attainment of foreign-born adopted children at age 15 related to the educational attainment and income of the adoptive parents in the Netherlands, and how does this compare to the parental effect on educational attainment of non-adopted children?" To answer this question, a large-scale register database is used, which contains information on the adoption status and educational level in secondary school of all 15-year old children living in the Netherlands in the years 2011-13.

\section{International adoptions in the Netherlands}

Even though adoption already became a legal option in several western countries as early as the $19^{\text {th }}$ century, it was legalized in the Netherlands only in 1956 (Hoksbergen, 2002), making the Netherlands one of the last countries in Europe to legalize adoption. Although the new law offered the opportunity to adopt both nationally and internationally, in the 1950s and 1960s it mainly concerned national adoptions. However, since the 1970s there has been a tremendous growth in international adoptions, and a sharp decline in national adoptions. This was the result of the rising popularity of the birth control pill in the 1960-1970's, and the introduction of the 'National Assistance Act' in 1963 which provided financial aid for people unable to work, making it easier for young single mothers to raise their children themselves (Sprangers, De Jong \& Van Zee, 2006). Since 1956, over 55,000 children have been adopted 
in the Netherlands of whom 39,000 of foreign-born origin. Nowadays, the number of nationally adopted children is very low.

Although the first internationally adopted children were predominantly born in other European countries such as Greece and Austria, the number of children adopted from European countries declined in the seventies. From that time onwards, international adoptees were mostly born in Asia - initially mainly in South Korea and later mostly in China - and South America, especially in Colombia (Sprangers et al., 2006). The proportion of adopted girls increased as well. Especially between 1995 and 2005, more girls than boys were adopted. The mean age of the children at adoption remained quite stable over time, on average between 2 and 3 years of age.

Dutch couples who want to adopt a foreign child must follow specific procedures and meet certain conditions. First, couples who submit the request for adoption both have to be younger than 42 and the difference between the oldest parent and the adoptee cannot be over 40 years. Couples also have to live in the Netherlands, have to hand in a medical certificate and a certificate of good conduct. Additionally, they have to attend several mandatory information and preparation sessions, especially to help them make an informed decision about the adoption. Also, the council of child protection examines the living conditions of the household, to ensure the adopted child is placed into a safe environment. Finally, there are costs involved in the adoption process, ranging from $€ 7,500$ to over $€ 35,000$.

Due to this strict adoption procedure, parents with adopted children differ on average from parents with biological children on several characteristics. In general, parents who adopt a child have first tried to have children of their own. Hence, adoptive parents are generally older and married for a longer period of time when they have their first child than biological parents (Hoksbergen, 1991). Also, due to, inter alia, the high adoption costs, adoptive parents 
are generally higher educated and have a higher household income compared to parents with biological children.

\section{Theory}

\subsection{Effect of family background}

In the literature, three main explanations are suggested for the association between parents' socioeconomic status (SES) and children's educational attainment within families with biological children (e.g. Becker \& Tomes, 1986; Solon, 2004). Some of these explanations also lead one to expect an association between parental SES and children's educational attainment within families with adopted children, whereas others do not.

The first mechanism argues that children's educational attainment is influenced by parents via the transmission of cultural capital (Bourdieu, 1973). Cultural capital can be seen as the entity of attitudes, preferences, knowledge, skills, behaviours, goods and credentials connected to a specific status (Lamont \& Lareau, 1988). Parents transmit their cultural capital to their children. Parents who have a high social status transmit cultural capital that helps children, for instance, to know how to behave properly according to high status culture (Lareau, 2011). Hence, the knowledge, skills and aspirations parents with high cultural capital transmit to their children and the examples they set for work effort and how to behave in school will help their children attain a high education. We expect both biological children as well as adopted children to profit from parents' cultural capital. In this study we use parental educational attainment as a proxy for cultural capital (Bourdieu, 1973; Jonsson, 1987). Although educational attainment does not completely capture the notion of cultural capital as defined above, it does capture those aspects of cultural capital that are especially related to (and help with) formal education, which is the main interest of this study. We 
hypothesize that the higher the educational attainment of parents of biological and adopted children is, the higher the children's educational attainment (hypothesis 1).

Another explanation for the association between parental SES and children's educational attainment stresses the importance of a family's financial capital (Becker \& Tomes, 1986; Leibowitz, 1974). Families with higher financial capital, have more economic resources to invest in their children, which can subsequently aid their children's school performance. For instance, they are better able to pay for homework assistance or tutoring when needed. In addition to this direct effect of economic resources, financial capital also indirectly affects children's educational achievement as it provides goods and (social) resources that can positively influence performance. Parents with more financial capital, for instance, generally live in better neighbourhoods, providing a potential network of friends with high status cultural capital regardless of the parent's cultural capital. Also, children of wealthier parents are more likely to have, for example, their own room or their own laptop, which can be beneficial for studying and doing homework properly. Hence, we expect that children with higher-income parents are more likely to attain a higher level of education, which is also referred to as the economic capital hypothesis (Boudon, 1974). Again, it is likely that this applies to both biological and adopted children. Therefore. we hypothesize that the higher the income of parents of biological and adopted children is, the higher the children's educational attainment (hypothesis 2).

The third mechanism argues that the association between family background and children's educational attainment is caused by genetic transmission (Leibowitz, 1974). As parents pass their genes on to their biological children, parents and children have partly equal genetically based traits that may hinder or foster educational attainment and economic success. Children's IQ, cognitive abilities and educational attainment are all examples of partially inherited abilities (Anger \& Heineck, 2010; Plomin \& Spinath, 2004; De Zeeuw et 
al., 2015; Okbay et al., 2016). Hence, the association between parents' educational attainment and income and the child's educational attainment might, thus, be partially due to genetic transmission and partially due to actual cultural and economic transmission. Since (internationally) adopted children are not genetically related to their adoptive parents, the intergenerational effect in adoptive families cannot be due to genetic transmission and thus can only be attributed to "nurture". Hence, in the presence of genetic transmission we expect the intergenerational effect to be larger for biologically related children than for adopted children. Therefore we hypothesize that the effect of parents' educational attainment and income on children's educational attainment will be smaller for adopted children than for biological children (hypothesis 3).

\subsection{Effect of adoption}

The educational attainment of adopted children will not only be affected by family background characteristics, but most likely by characteristics related to the adoption itself as well (Björklund \& Richardson, 2001). Hence, it is important to take into account adoption characteristics that might impede or facilitate the educational attainment of internationally adopted children.

Before adopted children arrive in their new adoptive home, they often have suffered from multiple negative experiences. Some of these, such as separation from the biological mother, are encountered by all adopted children. Other negative experiences are more likely to be encountered by children who were adopted at a later age, e.g. several separations from caretakers and the experience of institutionalization. This all enhances the likelihood that they have been exposed to deprivation with respect to attention, stimulation, emotional bonding, nutrition and medical care (Juffer \& IJzendoorn, 2005). Subsequently, this might induce several problems later in life, e.g. difficulties in establishing secure attachment, behavioural 
problems, and delayed development, putting adopted children at an elevated risk of maladjustment and potentially hindering their educational performance (Verhulst, Althaus \& Versluis-den Bieman, 1990). The earlier an adopted child is placed in the adoptive home, the less likely a child has experienced prolonged exposure to several of these potentially negative experiences (Bohman, 1970). Moreover, international adoptees that were adopted at a later age will have more difficulties in coping with changes in language, culture and environment, making it harder for them to integrate in their new country and possibly impeding their educational performance. Hence, we expect adoption age to be negatively related to the educational attainment of the adopted child.

Additionally, the country of birth might also be related to an adopted child's educational attainment (Björklund \& Richardson, 2001; Juffer, 2008). If the child is adopted from a very poor country, the likelihood that the biological parents were subjected to poverty, and thus the chance that the child lacked adequate prenatal and postnatal health care, suffered from malnutrition during pregnancy or experienced appalling circumstances in low-quality institutional settings, is enhanced. Again, these experiences potentially cause later life problems, possibly hindering a child's educational attainment. In contrast, in a country like China children were often registered for adoption due to the one-child policy (Juffer, 2008). In all likelihood, these children have at least received better prenatal and perinatal medical care than children that were registered for abortion due to poverty or drug abuse (Cohen, Lojkasek, Yaghoub Zadeh, Pugliese \& Kiefer, 2008). Thus, we expect the deprivation in the country of birth to negatively influence the adopted child's educational attainment.

\section{Data and Methods}

\subsection{Data and study population}


The data used in this study are retrieved from the System of Social statistical Datasets (SSD) of Statistics Netherlands (Bakker, Van Rooijen \& Van Toor, 2014). The SSD combines a vast number of administrative registers, among which the population register (containing personal characteristics, marital status, family relationships, household structure), tax registers (e.g. income), and educational registers (educational level, enrolment in education). Most registers are longitudinal and cover the complete Dutch population, making these data exceptionally well suited for research on intergenerational transmission.

Information on adoption status is based on data from the Dutch Immigration and Naturalisation Service (INS), which provide migration motives of non-Dutch immigrants. These data are combined with additional information from the Dutch population register on the country of birth and, especially, the date of birth versus the date at which the parent-child relationship was legally recognised. For non-adopted children, the date of legal recognition is the birth date but for adopted children, the legal parent-child relationship is established only after birth. The data include only adoptions where neither parent is the biological parent, i.e. excluding adoptions by stepparents. Data on adoptions are available from 1995 onwards.

We selected three complete birth cohorts of adopted and non-adopted children born between the 1st of October 1995 (first year in which adopted children can be distinguished in the data) and 1st of October 1998 (last birth cohort for which data on enrolment in secondary school at age 15 were available, in 2013). The initial sample contained 589,726 15-year old children living in the Netherlands in the years 2011-2013, of whom 2,689 adopted children. National adoptees $(4.1 \%)$ were excluded from the sample, as we cannot ensure that they are biologically unrelated to their adoptive parents (e.g. adopted by nephew, aunt) or otherwise resemble their adoptive parents due to selective placement. Moreover, children were removed from the sample when they did not live with either of their adoptive or biological parents anymore or when one of their parents died or emigrated, as these cases represent specific and 
disruptive family circumstances that are known to have negative consequences for children's outcomes. Children whose parents were born before 1956 were also excluded, as no reliable information on the educational attainment of these parents is available. This resulted in a research population of 504,279 non-adopted children and 2,142 foreign-born adopted children. An additional 69,701 cases were dropped from the analysis due to missing data on our variables. The final sample included 436,720 children, of whom 434,928 non-adopted and 1,792 internationally adopted children.

\subsection{Dependent variable}

In this study, the educational attainment of the child is operationalized as the child's level of enrolment in secondary school at age fifteen. Data are derived from educational registers maintained by the Ministry of Education, Culture and Science. We distinguish between four levels of secondary education that prepare for low, mid-level, higher vocational, and university education respectively. Subsequently, these levels are converted into scores on the ISLED-scale (the International Standard Level of Education) (Schröder \& Ganzeboom, 2013), as follows: lower vocational education $(=29.34)$, lower general secondary education $(=45.27)$, higher general secondary education $(=62.30)$ and pre-university education $(=71.92)$. The ISLED-scale is chosen, because it converts ordinal data into a well-validated continuous variable with a range of $0-100$ that is easy to interpret ${ }^{3}$. Moreover, the ISLED-scale is a highly comparative measure cross-nationally, which enhances comparability and replicability for future research.

The level of enrolment in secondary school at age fifteen is a suitable measurement point, since in the third year of secondary school, when children are 14-15, Dutch school levels have differentiated to prepare for specific types and levels of diplomas. Moreover,

\footnotetext{
${ }^{3}$ Treating this variable as an ordinal measure in the analyses provided us with similar outcomes.
} 
previous Dutch research showed that in the Netherlands track assignment is strongly associated with later educational careers (Tolsma \& Wolbers, 2010), as well as other later-life outcomes, e.g. final educational attainment and labour market outcomes (Borghans, Diris, Smits \& De Vries, 2012).

\subsection{Independent variables}

Father's and mother's educational attainment: Information on educational attainment of adults is extracted from the central register of enrolment in higher education (CRIHO). This register is available from 1986 onwards and contains information on diplomas in higher (i.e. tertiary) education: higher vocational education and university education. Information on non-tertiary education, e.g. secondary vocational education, is only integrally available in registers for very young cohorts graduating after 2003. Therefore, in this study we could not distinguish between low and midlevel education. We could, however, differentiate higher education in two detailed levels. So, parents are classified in (1) low/midlevel education, (2) completed higher vocational education and (3) completed university education. Since the register only contains information on diplomas from 1986 onwards, we may underestimate the level of tertiary education of old parents. Parents who graduated before 1986, as well as parents who studied abroad, will be incorrectly classified as not having a high education. Therefore, we excluded respondents with parents who were born before 1956. Exploratory analyses showed that the percentage of highly educated parents was lower among cohorts born before 1956, but stable among cohorts born from 1956 onwards.

Yearly household income: This variable measures yearly income of the household in which the child lives at age 15. The household's income is equalized, i.e. corrected for differences in composition and size of the household, so households' socio-economic situations can be directly compared. Moreover, after equalization, income is classified into 
percentiles based on the equalized income distribution of the complete Dutch population. Percentiles are used in order to avoid analytical problems with outliers. Also, the use of percentiles gives direct insight in the relative socio-economic position of families with adopted children, compared to that of other Dutch households. Hence, yearly household income in percentiles is a continuous variable ranging from 0 to 99.

Adoption status: This variable is a dummy variable indicating whether a child is adopted $(=1)$ or not $(=0)$.

\subsection{Control variables}

We controlled for father and mother's year of birth (both centered), child's gender ( $0=$ male, 1=female), family structure (whether the child lives with both biological/adoptive parents at age 15; $0=$ intact, $1=$ not intact), number of children present in the household and observation year (separate dummy variables for each birth cohort).

As discussed above, adoption characteristics can influence adoptees' educational attainment. Therefore, we also controlled for adoption age, a continuous variable measuring the age at which the child was placed with the adoptive parents, ranging from $0-11$. Moreover, we controlled for country of adoption, by creating 7 dummy variables: 'China', 'Colombia', 'Ethiopia', 'Haiti', 'India', 'South-Korea' and 'Taiwan'. We chose these seven countries, as that is where the majority of children in our research population were adopted from, with a minimum of 100 . As a reference category we have the dummy variable 'Other', including children who were adopted from another country than the seven countries listed above. Table 1 presents the descriptive statistics of all variables.

\subsection{Descriptive statistics}


In our research population of 436,720 15-year old children, 1,792 children are adopted $(0.4 \%)$. The largest group of these, $31.1 \%$, is adopted from China. Colombia is the second largest adoptive country. Moreover, Table 1 shows that on average children are adopted quite young. $81.2 \%$ are adopted at age two or earlier. Only $3.6 \%$ are older than five when they enter the Netherlands for adoption. $62.3 \%$ of the adopted children is female. This overrepresentation of girls is mainly due to adopted children from China, who are almost exclusively girls.

On average, the level of enrolment in secondary school of non-adopted 15 -year olds is higher than that of adoptees. For instance, $22.3 \%$ of the non-adopted are enrolled in preuniversity education, as opposed to $15.9 \%$ of the adopted children. Also, $26.7 \%$ of the nonadopted are enrolled in the lowest level of secondary education, while among adopted children this is $33.4 \%$.

Moreover, adopted children live in relatively good social and socio-economic circumstances. First, parents of adopted children are more often highly educated: $16.4 \%$ of mothers of adopted children have a high vocational or university education, as opposed to $12.0 \%$ of mothers of non-adopted, and a similar pattern is observed for fathers $(16.0 \%$ versus 13.4\%). Adopted children generally also live in households with a higher household income. Furthermore, adopted children live in smaller families; $77.1 \%$ live with one or no sibling as opposed to $64.7 \%$ in general, and adopted children more often live with both legal parents (89.0\% versus $80.4 \%$ ) as opposed to living in single parent households or stepfamilies.

[Insert Table 1 about here]

\subsection{Method}


We test our hypotheses using general linear models since our dependent variable, educational attainment of the child, is a continuous variable. First, separate OLS regression models are estimated for biological and adopted children. Next, we perform the analysis on the whole group. By including interactions between parental characteristics and being biologically related or not, we examine whether the differences in effects between the two groups are significant. Furthermore, we perform three sets of sensitivity analyses to examine whether our general analysis of intergenerational transmission might underestimate the effects of parental education and household income among adopted children. In a first set of sensitivity analyses, we examine whether our results are robust for alternative specifications of the parental educational attainment variable. In a second set of sensitivity analyses, we estimate sibling models to examine whether the results are the same within families with adopted as well as biological children. And, finally, in a third set of sensitivity analyses, we examine whether our results differ between different types of adopted children. Unless otherwise stated, we will not present full results of these sensitivity analyses, although these are available upon request from the authors.

\section{Results}

\subsection{Main analyses}

To test the first two hypotheses about the positive influence of parental education and income on children's educational attainment at age 15 among parents of biological and adopted children, separate OLS regression models were estimated for biological and adopted children. The results of these analyses are presented in Table 2. First, we discuss the results for biological children, for whom the results are presented on the left-hand side of the table.

[Insert Table 2 about here] 
For biological children, a statistically significant positive gradient of parental education is observed. This is true for both father's and mother's educational attainment. If the father has completed higher vocational education, the child's educational attainment at age 15 is 5.1 points higher than if the father has attained less than tertiary education, and the difference is even 7.9 points if the father has attained university education. The differences for mother's educational attainment are about the same size (6.2 and 8.7 points respectively). Thus, Hypothesis 1 is confirmed for biological children. We also observe a positive effect of household income, with a one percentile point increase in household income leading to a .12 point increase in the child's educational attainment at age 15 . Thus, biological children whose parents' household income is at the $75^{\text {th }}$ percentile of the household income distribution have - on average - a 6 points higher level of education at age 15 than children whose parents' household income is at the $25^{\text {th }}$ percentile of the distribution. Therefore, Hypothesis 2 is also confirmed for biological children.

We also briefly discuss the effects of other variables in the model. The later the birth year of the parents, i.e. the younger they are, the lower their children's educational attainment at age 15 is, and the significant effect for the quadratic term of birth year even indicates that this effect is strongest among very young parents. If parents are not living together when the child is 15 years of age, the educational attainment of the child is 1.8 points lower than if parents live together. No effect of the number of siblings is apparent. Boys perform a bit worse in school than girls -about 2 points. Finally, the average level of enrolment is a bit higher in 2013 than in 2012 and 2011. Together, these variables explain 16.3 per cent of the variance in children's educational attainment scores at age 15.

The results for adopted children are presented on the right-hand side of Table 2. No significant effect is observed for father's or mother's educational attainment, with one 
exception; the effect of father's university education comes close to statistical significance $(p=.07)$. Given that we formulated a directional hypothesis, a one-sided significance test would be appropriate, signifying that this effect is in line with Hypothesis 1. Overall, though, the evidence supporting Hypothesis 1 is very limited for adopted children. Sensitivity analyses suggest that the effect of father's university education is only present in Chinese adopted children; see below. The effect of household income supports Hypothesis 2. A onepercentile point increase in household income is associated with a .08 increase in the child's educational attainment at age 15 . Thus, adopted children whose parents' household income is at the $75^{\text {th }}$ percentile of the household income distribution have - on average - a 4 points higher level of education than children whose parents' household income is at the $25^{\text {th }}$ percentile of the distribution.

Among adopted children, no effect of parents' birth year is evident, indicating parents' age does not matter for the child's education at age 15 . Moreover, we also find no evidence for an effect of the family structure or the number of siblings. As among biological children, boys perform worse than girls. Finally, attainment scores in 2012 are a bit lower than in 2013. In all, these variables explain 6.4 per cent of the variance in educational attainment scores at age 15 , which is considerably less than for biological children.

Next, we turn to testing Hypothesis 3, stating that the effect of parents' education and income on children's education is smaller for adopted children than for biological children. To test this hypothesis, data on biological and adopted children are pooled and we add interaction variables between adoption status on the one hand, and parental education and household income on the other hand. Results are presented in Table 3.

[Insert Table 3 about here] 
Given that biological children are the reference category, the main effects for parental education and household income in this model reflect the effects for biological children. Indeed, these replicate the effects reported in Table 2. The interactions including parental education show that the effects for adopted children are significantly smaller than those for biological children. The same is true for the effect of household income; the effect is smaller for adopted children than for biological children. In addition, based on the separate analysis for adopted children, we know that the effect of parental education for adopted children is not just smaller than that for biological children, but actually hardly statistically significant at all. This all confirms Hypothesis 3. The other effects in Table 3 largely duplicate those for biological children in Table 2 .

In the direct comparison between biological and adopted children, only variables that were available for both sets of children were included. However, for adopted children we also have information on age at adoption and country of origin. Therefore, we repeat the analysis for adopted children including these variables, to see whether they affect the results. The estimates based on this OLS regression are presented in Table 4.

[Insert Table 4 about here]

A comparison of Table 4 and the right-hand part of Table 2 shows only a small change in the effects of parental education and income. After controlling for age at adoption and country of origin, the effect of paternal education is nonsignificant. The results for maternal education are not completely unequivocal: high vocational education reaches borderline significance $(\mathrm{p}=0.07)$, but university education is completely nonsignificant. The effect of household income remains positive and significant. Interestingly, adoption age and country of origin are strongly related to educational outcomes and explain much of the 
variance in educational attainment of adopted children. There is a clear negative effect of adoption age: a one-year increase in adoption age leads to a drop in the educational attainment score at age 15 of 1.1 point. There are also large differences in educational attainment by country of origin: children from China perform best (15.0 points better than children from 'other' countries), followed by children from South-Korea and Taiwan (10.4 and 8.5 points better than children from 'other' countries, respectively). Interestingly, the difference between boys and girls in this model is statistically nonsignificant, suggesting that the difference observed in Table 2 results from the overrepresentation of girls from China. Hence, it is country of origin rather than gender that explains this effect. In all, these variables explain 23.0 per cent of the variance in educational attainment scores at age 15 of adopted children.

\subsection{Sensitivity analysis 1: Alternative specifications of parental educational attainment}

In our main analyses, we are not able to differentiate among parents with less than tertiary education. This could possibly lead to an underestimation of the effect of parental education, an overestimation of the effect of income, and an overestimation of the difference in the effect of parent's education between adopted and non-adopted children (if adoptive parents are, for instance, more often midlevel educated and biological parents more often lowly educated). Therefore, we repeat the analyses using only the group of children whose parents both have tertiary education, as we can make a detailed distinction within this group (between those having a university education and those having a higher vocational education). For reasons of sample size -there were only 124 adopted children within this educational category- we collapse the variables measuring parent's educational attainment into a dummy variable that compares parents of whom either or both received university education to parents of whom neither received university education (i.e. both received higher vocational 
education). The results are comparable to those of the full sample. Parental educational attainment only matters for biological children, whereas household income matters for both biological and adopted children.

Moreover, in our main analyses we include educational attainment of both father and mother. Due to assortative mating, both parents' level of education might be highly correlated and potentially partial each other out. Therefore, we repeat our main analyses including either father's or mother's education rather than both. If we include only father's educational attainment, the results do not change much. Among adopted children, their father holding a university degree has a marginally significant effect on their educational attainment at age 15 $(\mathrm{b}=.2 .82, p=.06)$. If we only include mother's education, the results do not change much either. Among adopted children, their mother holding a higher vocational degree has a marginally significant effect on their educational attainment at age $15(b=1.99, p=.10)$.

Lastly, since education and income are often highly correlated, we also repeat our main analyses separately including either education or income instead of both. The results do not change much. Among adopted children, excluding parental education has basically no effect on the model; $\mathrm{R}^{2}$ decreases from 0.064 to 0.061 (for biological children, the $\mathrm{R}^{2}$ decreases much more strongly from 0.163 to 0.115$)$. Moreover, in this model the effect of income does not become much stronger $(\mathrm{b}=.09, p<.01)$. When excluding income from the model, the reduction in $\mathrm{R}^{2}$ is much more evident for adopted children; it decreases from 0.064 to 0.049 (for biological children from 0.163 to 0.130 ). In this model we do, however, find some effect of parental education on adopted children. The effect of father's university education is significant $(\mathrm{b}=3.39, p=.03)$ and also mother's higher vocational education reaches borderline significance $(b=2.30, p=.07)$. For biological children, the effects of father's and mother's educational level also are somewhat stronger when income is excluded. Most likely, the income effect is now partly taken over by the effect of education. Overall, 
the parental education effect for adopted children is much weaker than for biological children, adds almost nothing to the explained variance and is often hardly or not statistically significant. Our conclusion is that our results are robust to alternative specifications of parental educational attainment, providing us with limited support for hypothesis 1 for adopted children.

\subsection{Sensitivity analysis 2: Sibling analysis}

Adoptive families are a specific group. Quite possibly, they do not only differ from nonadoptive families on measured characteristics, but also on unmeasured ones, e.g. parenting skills. A sibling analysis allows to control for this unmeasured heterogeneity between adoptive and non-adoptive families. Unfortunately the number of families with both adoptive and biological children in our sample is limited $(\mathrm{N}=171)$, allowing for an exploratory analysis only. These 171 families include both internationally adopted $(\mathrm{N}=178)$ and biological children $(\mathrm{N}=197)$ born or adopted between 1995 and 1998.

Due to the small sample size, the number of observations within the categories of educational attainment of fathers and mothers is limited $(<20$ observations in some categories). In addition, within these 171 families, fathers' and mothers' educational attainment is correlated (Pearson correlation $=0.35$ ), which is especially problematic in small subpopulations. Therefore, we collapse the variables measuring parents' education into a dummy variable that compares parents of whom either or both received tertiary education to parents of whom neither received tertiary education.

Within these families, we observe statistically significant effects of parental education and household income for biological children, but not for adopted children. However, when including all children in one analysis, the interaction between parental educational attainment and being adopted is not statistically significant, and the interaction between household 
income and being adopted was only borderline significant $(b=-0.12, p<0.10)$. This means the effect of parental education is not significantly larger for the biological than for the adopted siblings, and the effect of household income only shows a trend to be larger for biological siblings -with biological siblings 'profiting' more from the household income than their adopted siblings. However, the small sample size limits the conclusions that can be drawn from this sensitivity analysis.

\subsection{Sensitivity analysis 3: Differences between adopted children}

Many adopted children suffer from types of deprivation, either pre-natal, perinatal or postnatal. Potentially the influence of the adoptive family's background is weaker the more deprivation children have experienced: cultural transmission processes may be disturbed due to traumas in early life. First, one can assume that deprivation is stronger if children are adopted at a relatively late age. Therefore, we examine whether the effects of parental education and income among adopted children depend on the adoption age, by adding interaction terms between parental education and household income on the one hand, and age at adoption on the other hand, to the model presented in Table 4. None of the interaction terms are significant, suggesting that the findings do not depend on adoption age. In addition, we restrict the sample of adopted children to those adopted before they turned age 1 , assuming that these children have experienced relatively little postnatal deprivation and were able to receive the full 'cultural impact' of the adoptive parents' education (Holmlund et al., 2011). Additionally, children that were adopted before one year of age have been found to form as secure attachments to their adoptive parents as biological children (e.g. Van den Dries et al., 2009), and secure attachments between parents and children greatly facilitate intergenerational transmission. Again, no changes in effects are observed, suggesting that the results hold both for children that are adopted at a very young age and those adopted at a somewhat older age. 
Second, it could be argued that Chinese children suffered less from pre-natal deprivation than children from other countries, since Chinese children in the 1990's were often given up due to the single-child policy and not because of poverty reasons. Therefore, we rerun our model on children born in China only. The effect of household income remains unchanged. However, the effect of the father having a university education becomes statistically significant $(\mathrm{b}=5.28, p=.02)$, indicating that there may be a role of parental education in understanding Chinese adopted children's educational attainment. This role appears to be small though: only the father's education is significant, not the mother's, and only university education, not lower tertiary education, is associated with higher educational attainment of the adopted children from China.

\section{Conclusion}

The results of this study point to the importance of parents' financial capital and cultural capital for the educational attainment of 15-year old children living with their biological parents. Although the results for adopted children also pointed to the importance of parent's financial capital, little evidence is found for the (non-genetic) transmission of cultural capital as measured by parents' educational level. Only in some models weak effects of parental

education were observed, whereas most models suggested no effect of parental education at all. This absence of transmission of educational attainment among adopted children suggests the importance of genetic transmission. Although various other studies on adopted children provided evidence for the importance of genes and financial capital as well, generally these studies also found evidence for the non-genetic transmission of parent's education (e.g., Björklund et al., 2006; Plug \& Vijverberg, 2003). Our study population (foreign-born) and the study context may be responsible for this difference. 
Most previous studies examined nationally adopted children. These children may resemble their adoptive parents as a result of selective placement by adoption agencies, or due to adoption by relatives. Some studies controlled for this by including information about the biological parents. In this study we dealt with this by investigating internationally adopted children. Selective placement is highly unlikely for foreign-born adoptees, reducing the probability of overestimating the intergenerational effects. Other studies investigating foreign-born adopted children generally also found much smaller and even no effect of parental educational attainment (Björklund \& Richardson, 2001; Haegeland et al., 2010; Holmlund et al., 2011).

Moreover, the results of our study, conducted in a relatively egalitarian context, fit with the idea outlined in the Introduction that cultural transmission could be stronger in less egalitarian countries. No strong effect of cultural transmission was found in Scandinavian studies (of foreign-born adoptees, Björklund \& Richardson, 2001; Haegeland et al., 2010) either, whereas a study on Korean adoptees in the United States did show a clear effect of parents' education (Sacerdote, 2007). The fact that the studies were conducted in different time periods however makes it difficult to draw conclusions about the effect of context and social policies. Specifically our study took place in a much more contemporary context. Western societies have gone through substantial changes in recent decades. The effect of parental characteristics on children's education may have changed over time as well. To get more insight into the effect of context, e.g. time period, social policies, on non-genetic transmission of inequality, more standardised research in various countries and over a longer period of time is needed.

This study used integral register data, which has some major advantages for this type of research. There is no selectivity due to non-response, information on parents, children and siblings can be connected, and small subpopulations -such as adopted children- can be 
studied without sample size issues. However, there are some limitations as well. First, the digital registers were available from 1995 onwards, limiting our research to 15-year olds. This has the advantage of enabling us to study a very recent population, and thus of reflecting the current situation in society. On the other hand, these children are in the middle of adolescence. At that age especially adopted children might be coping with issues of identity, possibly being temporarily less susceptible to parental influence. For a more complete picture, these children should be followed into adulthood. Second, in this dataset parental education could only be divided into three categories: low/midlevel education, completed higher professional education and completed university. Although we believe the distinction between having parents that have achieved tertiary education and having parents that have not achieved this is an important one, we would have preferred a more detailed measure of parental educational achievement. Since the category 'low/midlevel education' comprises a heterogeneous group, we might underestimate the (cultural) influence of parents' education on their children's schooling. The sensitivity analysis on the group of tertiary educated parents alone -among whom we could make a fine-grained distinction between university and high vocational educated- shows similar outcomes as the main results, confirming our conclusion about the limited importance of (non-genetic) transmission of cultural capital.

In line with previous research, we found that parental income is related to educational attainment of adopted children. This might point to the importance of family finances in school success (e.g., own room, computer). In addition, although The Netherlands does not have a school system like the US or the UK where good quality schools are only accessible for parents with a higher income, it does have institutes that offer additional tutoring and help with organising homework that are quite expensive. Hence, financial capital might be important for the reproduction of inequality in the Netherlands. We cannot rule out, however, that part of the effect of income is an indirect effect of unobserved qualities or characteristics 
of parents such as parenting skills (Plug \& Vijverberg, 2005) or an effect of the unobserved part of parent's educational level.

Studies on intergenerational transmission examining adopted children need to take into account certain issues. First, adoption procedures tend to select for potential parents who have some money -adoption can be expensive- and favourable parenting characteristics. Whenever the data allow it, it is vital to attempt to compare adopted and biological siblings who are raised within the same family in order to correct for the fact that adoptive families might be a very selective group. In our study, although data were limited, the general patterns of our main analyses were confirmed by our sibling analysis. Second, adopted children, especially those born in poor countries, are often born and raised in adverse circumstances with higher risks of illnesses and nutritional and emotional deprivation. It could be argued that such early traumatic experiences may disturb the bonding with the adoptive parents, and therefore also disturb intergenerational transmission. Hence, examining intergenerational transmission within adopted families potentially underestimates non-genetic intergenerational effects. This issue can be addressed by studying foreign-born children that are adopted at a very young age, and thus are only exposed to a relatively short period of deprivation. In our study, focusing on children that were adopted before the age of one year, we found similar outcomes as those for our full sample of adoptive children. For Chinese children however, who generally have experienced less adverse pre- and perinatal circumstances, we did find a limited effect of father's university education.

In conclusion, we found that educational attainment of foreign adopted children is related to the adopted parents' household income, but hardly to adopted parents' education. This suggests the importance of economic and genetic transmission and provides no substantial support for the transmission of cultural capital at this age. Perhaps the transmission of cultural capital becomes more important at later ages or for other outcomes, 
such as norms and values or health behaviour. Adoption characteristics, i.e. adoption age and adoption country, strongly influences adopted children's education.

\section{References}

Anger, S., \& Heineck, G. (2010). Do Smart Parents Raise Smart Children? The Intergenerational Transmission of Cognitive Abilities. Journal of Population Economics, 23(3), 1255-1282.

Bakker, B. F. M., van Rooijen, J., \& van Toor, L. (2014). The System of social statistical datasets of Statistics Netherlands: An integral approach to the production of registerbased social statistics. Statistical Journal of the IAOS, 30(4), 411-424.

Becker, G. S., \& Tomes, N. (1986). Human Capital and the Rise and Fall of Families. Journal of Labor Economics, 4(3), 1-39.

Björklund, A., \& Richardson, K. (2001). The Educational Attainment of Adopted Children Born Abroad: Swedish Evidence. Mimeo, University of Stockholm.

Björklund, A., Lindahl, M., \& Plug, E. (2006). "The Origins of Intergenerational Associations: Lessons from Swedish Adoption Data." Quarterly Journal of Economics, 121(3), 999-1028.

Björklund, A., Jäntti, M., \& Solon, G. (2007). Nature and nurture in the intergenerational transmission of socioeconomic status: evidence from Swedish children and their biological and rearing parents. IZA Discussion Paper Series, No. 2665.

Black, S. E., Devereux, P. J., \& Salvanes, K. G. (2005). Why the Apple Doesn't Fall Far: Understanding Intergenerational Transmission of Human Capital. American Economic Review, 95(1), 437-49.

Blanden, J. (2013). Cross-national rankings of intergenerational mobility: a comparison of approaches from economics and sociology. Journal of Economic Surveys, 27(1), 3873.

Blau , P. M., \& Duncan, O. D. (1967). The American Occupational Structure. New York: Wiley.

Bohman, M. (1970). Adopted Children and their Families. Stockholm: Proprius.

Borghans, L., Diris, R., Smits, W., \& de Vries, J. (2012). The Impact of Early Tracking on Later-life Outcomes: An Instrumental Variable Approach. Discussion Paper, 7 (143).

Bouchard, T. J., Jr., Lykken, D. T., McGue, M., Segal, N. L., \& Tellegen, A. (1990) Sources of human psychological differences: the Minnesota study of twins reared apart. Science, 250(4978), 223-228. 
Boudon, R. (1974). Education, Opportunity, and Social Inequality. New York: John Wiley \& Sons.

Bourdieu, P. (1973). Cultural Reproduction and Social Reproduction. In R. Brown (Ed.), Knowledge, Education and Cultural Change (pp. 71-112), London: Tavistock.

Cohen, N. J., Lojkasek, M., Yaghoub Zadeh, Z., Pugliese, M., \& Kiefer, H. (2008). Children adopted from China: A longitudinal study of their growth and development. Journal of Child Psychology and Psychiatry, 49(4), 458-468.

De Zeeuw, E. L., De Geus, E. J., \& Boomsma, D. I. (2015). Meta-analysis of twin studies highlights the importance of genetic variation in primary school educational achievement. Trends in Neuroscience and Education, 4(3), 69-76.

Erikson, R., \& Rudolphi, F. (2010). Change in Selection to Upper Secondary School Primary and Secondary Effects in Sweden. European Sociological Review, 26(3), 291-305.

Haegeland, T., Kirkeboen, L., Raaum, O., \& Salvanes, K. G. (2010). Why Children of College Graduates Outperform their Schoolmates: A Study of Cousins and Adoptees. IZA Discussion Paper Series, No. 5369.

Haveman, R., \& Wolfe, B. (1995). The Determinants of Children's Attainments: A Review of Methods and Findings. Journal of Economic Literature, 33(4), 1829-78.

Hoksbergen, R. A. C. (1991). Waarom adopteren mensen een kind? In R. Hoksbergen, \& H. Walenkamp (Eds.), Kind van andere ouders, theorie en praktijk van adoptie (pp. 6783). Houten: Bohn Stafleu Van Loghum.

Holmlund, H., Lindahl, M., \& Plug, E. (2011). The Causal Effect of Parents' Schooling on Children's Schooling: A Comparison of Estimation Methods. Journal of Economic Literature, 49(3), 615-651.

Jonsson, J. O. (1987). Class Origin, Cultural Origin and Educational attainment. European Sociological Review, 3(3), 229 - 242.

Juffer, F. (2008). De ontwikkeling van interlandelijk geadopteerden: een overzicht van onderzoek. Justitiele verkenningen, 34(7), 38-53.

Juffer, F., \& Van IJzendoorn, M. H. (2005). Behavior problems and mental health referrals of international adoptees: A meta-analysis. The Journal of the American Medical Association, 293(20), 2501-2515.

Lamont, M., \& Lareau, A. (1988). Cultural Capital: Allusions, Gaps and Glissandos in Recent Theoretical Developments. Sociological Theory, 6(2), 153-168.

Lareau, A. (2011). Unequal Childhoods. Class, Race, and Family Life, 2nd edition. Berkeley, CA: University of California Press.

Liu, H., \& Zeng, J. (2009), "Genetic ability and intergenerational earnings mobility”, Journal of Population Economics, 22(1), 75-95.

Leibowitz, A. (1974). Home Investments in Children. Journal of Political Economy, 82(2), 111-131.

OECD (2011). Causes of Growing Income Inequality in OECD Countries. OECD Publishing: Paris.

Okbay, A., Beauchamp, J. P., Fontana, M. A., Lee, J. J., Pers, T. H., Rietveld, C. A., ... \& Oskarsson, S. (2016). Genome-wide association study identifies 74 loci associated with educational attainment. Nature, 533(7604), 539-542. 
Oreopoulos, P., Page, M. E., \& Stevens, A. H. (2006). The Intergenerational Effects of Compulsory Schooling. Journal of Labor Economics, 24(4), 729-60.

Peter, K., \& Horn, L. (2005). Gender differences in participation and completion of undergraduate education and how they have changed over time (NCES 2005-169). U.S. Department of Education, National Center for Education Statistics. Washington, DC: U.S. Government Printing Office.

Plomin, R., \& Spinath, F. M. (2004). Intelligence: Genetics, Genes, and Genomics. Journal of Personality and Social Psychology, 86(1), 112-129.

Plug, E. (2004). Estimating the Effect of Mother's Schooling on Children's Schooling Using a Sample of Adoptees. American Economic Review, 94(1), 358-368.

Plug, E., \& Vijverberg, W. (2003). Schooling, Family Background, and Adoption: Is It Nature or Is It Nurture? Journal of Political Economy, 111(3), 611-641.

Plug, E., \& Vijverberg, W. (2005). Does Family Income Matter for Schooling Outcomes? Using Adoptees as a Natural Experiment. Economic Journal, 115(506), 879-906.

Sacerdote, B. (2007). How Large Are the Effects from Changes in Family Environment? A Study of Korean American Adoptees. Quarterly Journal of Economics, 122(1), 119157.

Scarr, S., \& Weinberg, R. A. (1994). Educational and Occupational Achievements of Brothers and Sisters in Adoptive in Biological Related Families. Behavior Genetics, 24(4), 301-325.

Schröder, H., \& Ganzeboom, H. B. G. (2013). Measuring and Modelling Level of Education in European Societies. European Sociological Review, 30(1), 119-136.

Solon, G. (2002). Cross-Country Differences in Intergenerational Earnings Mobility. The Journal of Economic Perspectives, 16(3), 59-66.

Solon, G. (2004). A Model of Intergenerational Mobility Variation over Time and Place. In M. Corak (Ed.), Generational Income Mobility in North America and Europe (pp.3847). Cambridge: Cambridge University Press.

Sprangers, A., De Jong, J., \& De Zee, M. (2006). Halve eeuw adopties in Nederland. Demos, Bulletin over Bevolkingen Samenleving, 22(10), 97-101.

Tolsma, J., \& Wolbers, M. (2010). Naar een open samenleving? Recente ontwikkelingen in sociale stijging en daling in Nederland. Den Haag: Raad voor Maatschappelijke Ontwikkeling.

Van den Dries, L., Juffer, F., van IJzendoorn, M. H., \& Bakermans-Kranenburg, M. J. (2009). Fostering security? A meta-analysis of attachment in adopted children. Children and youth services review, 31(3), 410-421.

Verhulst, F. C., Althaus, M., \& Versluisden Bieman, H. J. M. (1990). Problem behaviour in international adoptees: II. Age at Placement. Journal of the American Academy of Child and Adolescent Psychiatry, 29(1), 104-111. 


\section{Tables}




\begin{tabular}{|c|c|c|c|c|c|}
\hline & Mean & (SD) & Mean & (SD) & Range \\
\hline Educational level & 50.933 & $(16.182)$ & 48.079 & $(16.003)$ & $29.34-71.92$ \\
\hline \multicolumn{6}{|l|}{ Father's educational attainment } \\
\hline Low/midlevel & .866 & & .840 & & $0 / 1$ \\
\hline High vocational & .081 & & .092 & & $0 / 1$ \\
\hline University & .053 & & .068 & & $0 / 1$ \\
\hline \multicolumn{6}{|l|}{ Mother's educational attainment } \\
\hline Low/midlevel & .881 & & .836 & & $0 / 1$ \\
\hline High vocational & .078 & & .105 & & $0 / 1$ \\
\hline University & .042 & & .059 & & $0 / 1$ \\
\hline Household income, in percentiles & 53.668 & $(26.765)$ & 60.319 & $(25.288)$ & $0-99$ \\
\hline Adoption age & - & & 1.401 & $(1.773)$ & $0-11$ \\
\hline \multicolumn{6}{|l|}{ Adoption country } \\
\hline China & - & & .311 & & $0 / 1$ \\
\hline Colombia & - & & .180 & & $0 / 1$ \\
\hline Ethiopia & - & & .057 & & $0 / 1$ \\
\hline Haiti & - & & .057 & & $0 / 1$ \\
\hline India & - & & .064 & & $0 / 1$ \\
\hline South-Korea & - & & .065 & & $0 / 1$ \\
\hline Taiwan & - & & .062 & & $0 / 1$ \\
\hline Other & - & & .266 & & $0 / 1$ \\
\hline Father's birth year ${ }^{\text {a }}$ & 1964.557 & $(4.171)$ & 1960.733 & $(3.436)$ & $1956-1986$ \\
\hline Mother's birth year ${ }^{a}$ & 1966.810 & $(4.195)$ & 1962.386 & $(3.710)$ & $1956-1985$ \\
\hline Gender (female) & .496 & & .623 & & $0 / 1$ \\
\hline Family structure (not intact) & .196 & & .110 & & $0 / 1$ \\
\hline Number of children & 2.367 & $(.977)$ & 2.132 & $(.800)$ & $1-18$ \\
\hline \multicolumn{6}{|l|}{ Observation year } \\
\hline 2011 & .278 & & .239 & & $0 / 1$ \\
\hline 2012 & .347 & & .335 & & $0 / 1$ \\
\hline 2013 & .375 & & .426 & & $0 / 1$ \\
\hline
\end{tabular}

Table 1. Descriptive statistics of dependent, independent and control variables.

${ }^{a}$ These variables are mean centered in the analysis.

Table 2 Linear regression models of educational attainment at age 15, by type of children

\begin{tabular}{rrrr}
\multicolumn{2}{c}{ Biological children } & \multicolumn{2}{c}{ Adopted children } \\
$\mathrm{b}$ & se & $\mathrm{b}$ & se \\
\hline
\end{tabular}




\begin{tabular}{|c|c|c|c|c|c|c|}
\hline Intercept & 44.55 & $* *$ & .10 & 45.25 & $* *$ & 1.69 \\
\hline \multicolumn{7}{|l|}{ Father's educational attainment } \\
\hline High vocational & 5.10 & $* *$ & .09 & .05 & & 1.32 \\
\hline University & 7.87 & $* *$ & .11 & 2.82 & $\dagger$ & 1.53 \\
\hline \multicolumn{7}{|l|}{ Mother's educational attainment } \\
\hline High vocational & 6.18 & $* *$ & .09 & 1.65 & & 1.25 \\
\hline University & 8.66 & $* *$ & .12 & -1.56 & & 1.63 \\
\hline Household income, in percentiles & .12 & $* *$ & .00 & .08 & $* *$ & .02 \\
\hline Family structure (not intact) & -1.79 & $* *$ & .06 & .06 & & 1.23 \\
\hline Number of children & -.04 & $\dagger$ & .02 & -.43 & & .48 \\
\hline Father's birth year & -.16 & $* *$ & .01 & -.14 & & .20 \\
\hline Father's birth year squared & -.01 & $* *$ & .00 & -.03 & & .03 \\
\hline Mother's birth year & -.31 & $* *$ & .01 & -.26 & & .21 \\
\hline Mother's birth year squared & -.01 & $* *$ & .00 & .01 & & .02 \\
\hline Gender (male) & -1.95 & $* *$ & .05 & -5.11 & $* *$ & .78 \\
\hline \multicolumn{7}{|l|}{ Observation year } \\
\hline 2011 & -.36 & $* *$ & .06 & -1.36 & & .96 \\
\hline 2012 & -.30 & $* *$ & .05 & -1.83 & $*$ & .85 \\
\hline $\mathrm{R}^{2}$ & & .163 & & & .064 & \\
\hline $\mathrm{N}$ & & 34,928 & & & 1,792 & \\
\hline
\end{tabular}

Two-tailed test: $\uparrow \mathrm{p}<.10,{ }^{*} \mathrm{p}<.05,{ }^{* *} \mathrm{p}<.01$ 
Table 3 Linear regression model of educational attainment at age 15, combined for biological and adopted children

\begin{tabular}{|c|c|c|c|}
\hline & $\mathrm{b}$ & & se \\
\hline Intercept & 44.56 & $* *$ & .10 \\
\hline \multicolumn{4}{|l|}{ Father's educational attainment } \\
\hline High vocational & 5.10 & $* *$ & .09 \\
\hline University & 7.87 & $* *$ & .11 \\
\hline High vocational $*$ adopted & -4.97 & $* *$ & 1.25 \\
\hline University $*$ adopted & -4.73 & $* *$ & 1.46 \\
\hline \multicolumn{4}{|l|}{ Mother's educational attainment } \\
\hline High vocational & 6.18 & $* *$ & .09 \\
\hline University & 8.66 & $* *$ & .12 \\
\hline High vocational $*$ adopted & -4.74 & $* *$ & 1.12 \\
\hline University $*$ adopted & -9.66 & $* *$ & 1.55 \\
\hline Household income, in percentiles & .12 & $* *$ & .00 \\
\hline Household income $*$ adopted & -.05 & $* *$ & .01 \\
\hline Family structure (not intact) & -1.78 & $* *$ & .06 \\
\hline Number of children & -.04 & $\dagger$ & .02 \\
\hline Father's birth year & -.16 & $* *$ & .01 \\
\hline Father's birth year squared & -.01 & $* *$ & .00 \\
\hline Mother's birth year & -.31 & $* *$ & .01 \\
\hline Mother's birth year squared & -.01 & $* *$ & .00 \\
\hline Gender (male) & -1.97 & $* *$ & .05 \\
\hline \multicolumn{4}{|l|}{ Observation year } \\
\hline 2011 & -.37 & $* *$ & .06 \\
\hline 2012 & -.31 & $* *$ & .05 \\
\hline Adoption status (adopted) & -1.81 & $*$ & .91 \\
\hline $\mathrm{R}^{2}$ & \multicolumn{3}{|c|}{.16} \\
\hline $\mathrm{N}$ & \multicolumn{3}{|c|}{436,720} \\
\hline
\end{tabular}

Two-tailed test: $\uparrow \mathrm{p}<.10,{ }^{*} \mathrm{p}<.05,{ }^{*} * \mathrm{p}<.01$ 
Table 4 Linear regression model of educational attainment at age 15, adopted children only

\begin{tabular}{|c|c|c|c|}
\hline & $\mathrm{b}$ & & $\mathrm{se}$ \\
\hline Intercept & 39.00 & $* *$ & 1.76 \\
\hline \multicolumn{4}{|l|}{ Father's educational attainment } \\
\hline High vocational & .10 & & 1.20 \\
\hline University & 2.11 & & 1.40 \\
\hline \multicolumn{4}{|l|}{ Mother's educational attainment } \\
\hline High vocational & 2.08 & $\dagger$ & 1.14 \\
\hline University & -.67 & & 1.49 \\
\hline Household income, in percentiles & .08 & $* *$ & .01 \\
\hline Family structure (not intact) & .90 & & 1.13 \\
\hline Number of children & .11 & & .44 \\
\hline Father's birth year & .07 & & .19 \\
\hline Father's birth year squared & -.03 & & .02 \\
\hline Mother's birth year & .03 & & .19 \\
\hline Mother's birth year squared & .02 & & .02 \\
\hline Gender (male) & .01 & & .79 \\
\hline \multicolumn{4}{|l|}{ Observation year } \\
\hline 2011 & .00 & & .88 \\
\hline 2012 & -.79 & & .78 \\
\hline Adoption age & -1.07 & $* *$ & .22 \\
\hline \multicolumn{4}{|l|}{ Adoption country } \\
\hline China & 15.04 & $* *$ & 1.08 \\
\hline Colombia & 1.02 & & 1.10 \\
\hline Ethiopia & 2.16 & & 1.60 \\
\hline Haiti & -1.40 & & 1.62 \\
\hline India & -1.31 & & 1.55 \\
\hline South-Korea & 10.40 & $* *$ & 1.57 \\
\hline Taiwan & 8.51 & $* *$ & 1.59 \\
\hline $\mathrm{R}^{2}$ & & .23 & \\
\hline $\mathrm{N}$ & & 1,792 & \\
\hline
\end{tabular}

Two-tailed test: $\uparrow \mathrm{p}<.10, * \mathrm{p}<.05, * * \mathrm{p}<.01$ 